\title{
Day of dialogue on multipurpose prevention technologies: Toward clarity in nomenclature
}

\author{
Martha Brady \\ Population Council \\ C. Elizabeth McGrory
}

Follow this and additional works at: https://knowledgecommons.popcouncil.org/departments_sbsr-pgy

Part of the Demography, Population, and Ecology Commons, International Public Health Commons, Pharmaceutics and Drug Design Commons, and the Women's Health Commons How does access to this work benefit you? Let us know!

\section{Recommended Citation}

Brady, Martha and C. Elizabeth McGrory. 2011. "Day of dialogue on multipurpose prevention technologies: Toward clarity in nomenclature," Meeting notes. New York: Population Council. 


\section{Facilitating Regulatory Approval of Multipurpose Prevention}

Technologies (MPTs) for Reproductive Health

\section{Day of Dialogue \\ Multipurpose Prevention Technologies: \\ Toward Clarity in Nomenclature}

February 2, 2011
Population Council
Washington, DC

MEETING NOTES

Martha Brady, Population Council

Elizabeth McGrory, Consultant

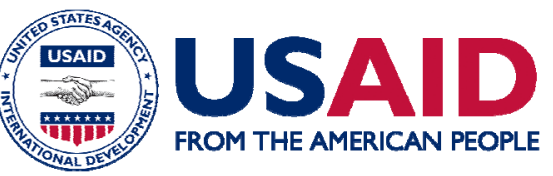

(1) Population Council 
This document was made possible through support provided by the United States Agency for International Development (USAID) under the terms of Cooperative Agreement No. AID-OAA-A-10-00072. The contents are the responsibility of the authors and do not necessarily reflect the views of USAID or the United States Government.

\section{(2 Population Council}

The Population Council conducts research worldwide to improve policies, programs, and products in three areas: HIV and AIDS; poverty, gender, and youth; and reproductive health.

Population Council

One Dag Hammarskjold Plaza

New York, NY 10017 USA

(212) 339-0500

pubinfo@popcouncil.org

www.popcouncil.org

(C) March 2011. The Population Council, Inc.

Any part of this publication may be photocopied without permission from the publisher provided that copies are distributed without charge and that full source citation is provided. The Population Council would appreciate receiving a copy of any materials in which the text is used. 


\title{
Notes from Population Council Day of Dialogue
}

\section{“Multipurpose Prevention Technologies: Toward Clarity in Nomenclature"}

\author{
Prepared by \\ Martha Brady and Elizabeth McGrory
}

Multipurpose prevention technologies (MPTs) that address women's sexual and reproductive health needs - through preventing unintended pregnancies and/or sexually transmitted infections, including HIV - could make a major contribution to global health. Unsafe sex is an enormous public health problem, leading to the second largest cause of illness and disability among women worldwide. It is also a major factor in female mortality, especially in low-resource settings. Products that provide simultaneous protection against unintended pregnancy and sexually transmitted infections (STIs), including HIV, could play a significant role in improving women's sexual and reproductive health.

Recognizing this need, USAID is supporting the newly launched Initiative on Multipurpose Prevention Technologies (IMPT) for sexual and reproductive health. Judy Manning from USAID provided an overview of the Agency's overarching objectives and how the IMPT fits into this work (see attached presentation). Building on its decades of support for developing contraceptives as well as products to prevent STIs, including HIV, USAID is working with other US agencies, as well as outside partners, to provide more focused support to facilitate research and development, regulatory approval, and introduction of MPTs through both ongoing and new awards. ${ }^{1}$

As part of this effort, the Population Council is spearheading work to clarify and inform regulatory pathways for MPTs. ${ }^{2}$ As outlined by Martha Brady from the Population Council in her overview presentation, MPTs are a unique and specialized subset of what regulatory authorities, including the US Food and Drug Administration (FDA), refer to as combination products. The FDA defines combination products as "a product comprised of two or more regulated components-any combination of a drug, device, and biological product-produced as a single entity." Importantly, such "combination products" are intended only to address a single indication. ${ }^{3}$ With respect to "multipurpose prevention products," the FDA has not published a proposed definition specifically for prevention products with multiple indications (see attached presentation).

This lack of definition means that the regulatory environment for MPTs can be challenging and uncertain. Given their sometimes diverse components and indications, MPTs often do not fit into the discrete categories-drug, device, or biologic-used by regulators to assess products. Even the term "MPT" can be somewhat imprecise, referring variously to a product that has multiple "purposes" or

\footnotetext{
${ }^{1}$ See http://www.cami-health.org/ for a description of the IMPT.

${ }^{2}$ See Population Council brief "Facilitating Regulatory Approval for Multipurpose Prevention Technologies for Sexual and Reproductive Health" for project details.

${ }^{3} 21$ CFR 3.2(e)
} 
indications, and can be comprised of one or more active drug, a device, an active drug combined with a device, more than one active drug combined with a device, and so forth. In the field of women's sexual and reproductive health these could refer to, for example:

- Combination products: active agent/s combined with a barrier device, or a delivery vehicle such as an intravaginal ring or gel designed to deliver one or more agents active against HIV and/or other STIs and/or a contraceptive agent;

- Broadly active single agents that could address more than one indication;

- Microbicides active against HIV and other STIs.

\section{Why this Day of Dialogue?}

Seeking to clarify this array of nomenclature and concepts, the Council convened a half-day meeting of diverse stakeholders (see attached participant list). The presence of staff from the US FDA also provided an opportunity to explore further where MPTs would fit within existing FDA guidance, as well as whether such guidance could and should be supplemented or amended to facilitate review of MPTs. While much of this initial discussion necessarily focused on the FDA's approaches, the Council will continue to explore approaches taken by other key regulatory agencies, including the European Medicines Agency (EMA).

These meeting notes summarize key points from the lively and wide-ranging discussion. The first section outlines where different types of products are reviewed within the FDA and existing processes that could be applied to MPTs. This is followed by a section that reviews what guidance exists and what else may be needed for review of products like MPTs that address two (or more) indications, including those with a single active, two actives, and multiple components. A number of people at the meeting have participated in developing the draft guidance on microbicides, and these notes also summarize how that guidance could potentially be applied to MPTs, and possible additions or modifications that may be needed. Finally, two brief sections summarize how the Council and other partners will continue to take this work forward.

Determining designation for products: What goes where at the FDA?

Candidate products undergo review at the FDA depending on their designation, as follows:

- Drugs: Center for Drug Evaluation and Research (CDER)

- Biologics: Center for Biologics Evaluation and Research (CBER)

- Device and Radioactive Therapy: Center for Devices and Radiological Health (CDRH)

Jurisdiction for review of combination products is determined by the Office of Combination Products (OCP) within the FDA, based on a given candidate's Primary Mode of Action (PMOA). ${ }^{4}$ The PMOA is the single mode of a combination product that provides the most important therapeutic action and is

\footnotetext{
${ }^{4}$ Guidance for Industry and FDA Staff "How to Write a Request of Designation (RFD)." http://www.fda.gov/Regulatorylnformation/Guidance/ucm126053.htm.
} 
expected to make the greatest contribution to the overall intended effects of the product. ${ }^{5}$ The OCP deals with products like drug-containing stents-which combine a drug and a device-and therefore can prompt uncertainty about where in the FDA structure they should be reviewed. The OCP is FDA-wide and makes its determinations about which sections of the agency to involve on a case-by-case basis depending on the specifics of the proposed product.

An important factor in the review of combination products is where the drug would fit within existing FDA structures. Some candidate multi-component drugs could be reviewed in one division of the FDA, while others may prompt review in two different divisions. FDA entities can collaborate in such reviews, but it is important to consider where primary decision making lies.

Existing guidance on combination products and on multiple indications is necessarily quite general given the wide range of products they must cover. These are designed to be quite flexible constructs that can be adapted for individual circumstances.

What guidance exists and what else is needed?

Population Council staff conducted a systematic review of three key guidance documents to determine whether and how they relate to MPTs for sexual and reproductive health:

- FDA/CDER - Guidance for Industry: Co-development of Two or More Unmarketed Investigational Drugs for Use in Combination (draft Dec. 2010) http://www.fda.gov/downloads/Drugs/GuidanceComplianceRegulatoryInformation/Guidances/ UCM236669.pdf

- FDA/OCP - Guidance for Industry and FDA Staff: Early Development Considerations for Innovative Combination Products (Sept. 2006) http://www.fda.gov/downloads/Regulatorylnformation/Guidances/ucm126054.pdf

- EMA - Guideline on Clinical Development of Fixed Combination Medical Products (Feb. 2009) http://www.tga.gov.au/docs/pdf/euguide/ewp/024095enfin.pdf

While the documents offer no specific guidance for combination products or MPTs as they relate to sexual and reproductive health (SRH), the group reviewed how this existing guidance would be applied to MPTs for SRH as part of determining whether additional guidance would be useful.

Guidance for two (or more) indications.....

In this context a "multipurpose product" means that approval would be sought for two (or more) indications. A critical distinction is whether the MPT is a single drug for multiple indications or a combination of two or more elements.

......for a single active

Several participants contributed their experience with seeking FDA approval for two or more indications of a single drug. Generally, approval for the two indications will be sought separately, with the sponsor

\footnotetext{
${ }^{5}$ Definition of Primary Mode of Action of a Combination Product, Published August 25, 2005 Final Rule. http://edocket.access.gpo.gov/2005/pdf/05-16527.pdf
} 
seeking approval for the first indication it can get first, and then conducting a separate clinical study to demonstrate safety and efficacy for the second indication. Technically, submissions for the two separate indications reside under separate Investigational New Drug Applications (IND). Most meeting participants who had worked in this arena felt it best to "keep it clean" with separate INDs for the two indications where submissions to the other IND could be cross referenced. This approach is generally more efficient because the IND can then be turned over to a New Drug Application (NDA) for that particular indication, and the FDA also generally prefers separate INDs. If needed, the applicant may choose to consult with the FDA, which can advise which approach would be most expeditious.

\section{.....for two actives}

The FDA guidance on co-development for developing two actives simultaneously maps out how to approach co-development for one indication. This guidance is necessarily broad, and another dimension would be needed to address approaches to developing two actives simultaneously for multiple indications. For a potential product with two active components, the guidance indicates that efficacy needs to be demonstrated for each separately, and then together. Several people queried whether there is any flexibility in this requirement, given the urgent public health need for MPTs and in those cases where evidence of efficacy is available for some of the active agents being used in a combination. For example, levonorgestrel has been used orally for four decades and is now being developed and tested for use in an intravaginal ring in combination with an antiretroviral agent for preventing both HIV and pregnancy. There is a great deal of evidence on oral use of levonorgestrel, however, it is not approved for use in a vaginal ring. It is not clear how to pursue product development with the new delivery system (intravaginal ring) in light of the overwhelming evidence of safety and efficacy of the oral formulation of this drug.

\section{....for multiple components}

While an MPT with two active agents may be developed for two separate indications, an MPT could also be comprised of more than two components. For example, in the case of a combined vaginal ring that may contain two drugs like levonorgestrel for contraception and tenofovir for HIV prevention, clarity may be needed about what would be considered the "first" indication. Microbicide rings are quite new. To date, FDA experience with intravaginal rings has focused predominantly on vaginal rings delivering hormonal contraceptive agents (for example, the NuvaRing ${ }^{\circledR}$ ). In this context, the vaginal ring has been viewed as the delivery device and is not an active component by itself. As with other areas, approaches will need to evolve and respond to new knowledge and new products. It may also be possible to approach some of the questions with pharmacokinetic and/or pharmacy-dynamic studies, but this would be determined on a case-by-case basis.

For products containing multiple investigational agents, FDA input may be sought early in the development process even prior to submission of a new IND. This may be accomplished through a preIND consultation where the FDA responds to sponsors' questions within a specified timeframe. 
Information about the pre-IND program can be found at the FDA website. ${ }^{6}$ Under an IND, sponsors are encouraged to consult the FDA throughout the development process.

How could the draft microbicide guidance be applied to MPTs?

The FDA is in the process of developing guidance for vaginal microbicides. This guidance will address relevant elements that could potentially be applied to or adapted for work on MPTs. Over the course of the meeting several participants drew on their experience with this process.

In this rapidly evolving area, the group in the FDA developing microbicide guidance is working to anticipate where the field is heading and respond accordingly by incorporating relevant issues. As with all guidance it has had to balance being general and specific, while remaining broad enough to encompass emerging approaches. The guidance currently under development has a section dedicated to combination products. This section does not currently deal with contraception, but it may be possible to do so if there is a felt need for such guidance and this is determined to be the best way to address it. Such a process would involve the Office of Women's Health and the Division of Reproductive and Urologic Drug Products.

The microbicide guidance is still being developed, so there is an opportunity to incorporate or address new areas, such as highlighting other technologies in the pipeline that could help inform the FDA about future products and needs. However, raising additional issues would likely further delay the guidance, so a balance must be struck between timeliness and addressing a more comprehensive set of topics. Following review within the FDA, the draft guidance will be open for public comment.

\section{Moving forward}

The need for specific dedicated guidance on MPTs remains something of an outstanding question, one that the Population Council will continue to explore and address. Given the diverse set of drugs, devices, and indications under the rubric of "MPTs," dedicated regulatory guidance may not be the best approach to facilitating review of MPTs. It may be too difficult to develop meaningful guidance to encompass the wide range of components and products being considered under the rubric of "MPTs."

There was some discussion about whether guidance specifically focused on products to prevent HIV and pregnancy would be useful. These products are both urgently needed and the focus of a number of current MPT development efforts. Such approaches mainly center on combining two products - one known to prevent HIV (like an antiretroviral) and one known to be contraceptive (like levonorgestrel). Guidance could help sponsors target their efforts, and anticipate timelines and resources needed. As outlined above, the draft microbicide guidance could potentially be expanded to address pregnancy prevention as well as HIV.

\footnotetext{
${ }^{6}$ http://www.fda.gov/Drugs/DevelopmentApprovalProcess/HowDrugsareDevelopedandApproved/ ApprovalApplications/InvestigationalNewDrugINDApplication/default.htm.
} 
While HIV and pregnancy prevention are clearly central to the IMPT, other product profiles are also being developed. Partners in the initiative are convening an upcoming "think tank" around target product profiles for MPTs. These examples may highlight other areas where guidance would be particularly useful.

The FDA develops new guidance in response to a need, which can be prompted by a sponsor or a pharmaceutical coalition or organization. If there is agreement on the need for guidance on MPTs, the Council and its partners in the IMPT could potentially advocate for such guidance and present such an argument to FDA for consideration.

The Population Council will continue to explore the need for new guidance or addition to existing guidance from the FDA, and if such guidance is needed, how best to make the case about why such guidelines would be needed and why they are important now. At the same time the Council will clarify regulatory pathways in the European Medicines Agency for MPTs and at other stringent regulatory authorities in key countries with a high burden of disease and where MPTs are needed and could be introduced.

Next steps

Based on the discussions and suggestions that emerged at this meeting, and in the context of other ongoing efforts in this initiative, the Population Council will work on several follow-up actions:

- Explore with the FDA the development of a question-and-answer document for MPTs for sexual and reproductive health that could be included on the FDA website.

- Population Council staff will prepare a "white paper" highlighting regulatory challenges for MPTs, drawing upon examples from products approved and in the pipeline. These brief "case studies" can help highlight whether current approaches are sufficient or whether specific guidance is needed for MPTs for sexual and reproductive health.

- Staff at the Council and WHO will share a draft of the "white paper" with colleagues in the EMA and possibly other key regulatory agencies to incorporate those agencies' thinking and approaches.

The Day of Dialogue drew together nearly thirty stakeholders, including IMPT partners, to think through some of the specific opportunities and challenges for the regulatory pathway for MPTs, and helped the Council chart next steps for its work in this area. The lively and productive discussion will help inform how best to facilitate regulatory approval for MPTs for sexual and reproductive health, a critical component in developing and delivering these urgently needed products to women. 


\title{
(2) Population Council
}

MULTIPURPOSE PREVENTION TECHNOLOGIES:

TOWARDS CLARITY IN NOMENCLATURE

\author{
Wednesday, February $2^{\text {nd }}, 2: 00-5: 00$ pm \\ Population Council \\ Washington, DC
}

Invitation List

Diana Blithe

Heather Boonstra

Martha Brady

Gina Brown

Marianne Callahan

Carolyn Deal

Jessica Cohen

Laneta Dorflinger

Arlene Fairfield

Tim Farley

Beverly Gallauresi

Polly Harrison

Anke Hemmerling

Bethany Young Holt

Maggie Kilbourne-Brook

Laurel Lagenaur

Judy Manning

Elizabeth McGrory

Jeff Meer

Ruth Merkatz

Scott Monroe

Charu Mullick

Heeyoung Park

Victor Paulus

Matthew Reeves

Naomi Rutenberg

Wayne Shields

Jeff Spieler

Alan Stone

John Townsend

Ashley Vij
$\mathrm{NIH}$

Guttmacher Institute

Population Council

$\mathrm{NIH}, \mathrm{OAR}$

CONRAD

$\mathrm{NIH}$

PATH

$\mathrm{FHI}$

PATH

WHO

FDA, Office of Women's Health

Sr. Advisor, AVAC; Consultant, Population Council; IMPT

UCSF

CAMI/PHI; IMPT

PATH

$\mathrm{NCl}$ Vaccine Branch; Osel Inc.

USAID

Consultant, Population Council

Public Health Institute; Global Health Technologies Coalition

Population Council

FDA, Div. Reproductive and Urologic Drug Products, CDER

FDA, Division of Antiviral Products, CDER

Population Council

Population Council

WomenCare Global

Population Council

ARHP

USAID

IMPT Advisory Committee

Population Council

USAID 